\title{
Confronting Health Communication Challenges Addressing Tuberculosis in Sri Lanka: Synopsis
}

\section{Enfrentando os Desafios de Comunicação em Saúde Abordar a Tuberculose no Sri Lanka: Sinopse}

\author{
Deepak Gupta \\ Formerly with UNFPA, UNICEF \& WHO - New Delhi \\ drguptad11@gmail.com
}

Kanthi Ariyarathne

Formerly with National Programme for Tuberculosis Control \& Chest Diseases - Sri Lanka ariyarathnekanthi@yahoo.com

\begin{abstract}
Abdul Cader Refai
National Programme for Tuberculosis Control \& Chest Diseases - Sri Lanka

rajaireshyamalikasdr@gmail.com

Shyamali Rathnayake

National Programme for Tuberculosis Control \& Chest Diseases - Sri Lanka

shyamalikasdr@gmail.com
\end{abstract}

As is widely recognized, Tuberculosis (TB) is an airborne infectious disease that poses a major global health challenge. In most countries, TB has been a public health concern and a priority especially in recent years, including in Sri Lanka. The estimated global incidence of active TB is 10 million with 1.8 million associated mortalities per year. WHO estimates that one-third of the global population has latent TB (WHO, 2016) with South-East Asia region accounting for $46.5 \%$ of the incident cases. Despite Sri Lanka being classified as a low-prevalence country, approximately 9,000 cases are recorded and notified on an annual basis (WHO, 2017).

In the context of United Nations Sustainable Development Goals (SDGs) and the WHO End TB Strategy, the Government of Sri Lanka (NPTCCD - National Programme for TB Control and Chest Diseases) has set forth the commitment to end 
the TB epidemic by 2025 while the world goals under the WHO strategy are for the year 2030. It is well recognized that universal health coverage, sustainable financing for multi-sectoral actions, rapid scale up of innovative approaches and tools, and discovery of new and better tools for prevention, diagnosis and treatment of $\mathrm{TB}$, together with the strategic focus on Health Communication (ACSM - Advocacy, Communication \& Social Mobilization) is fundamental to transform the fight.

Tuberculosis control in Sri Lanka has shown a significant progress with the thorough implementation of the DOTS strategy since 1995. With an end of over thirty years of unrest in northern and eastern provinces in 2009, the country successfully attained $100 \%$ DOTS coverage across the island.

Sri Lanka is poised to increase and thus, envisions the TB detection of at least $90 \%$ of incident cases (in all forms) by 2020 . Similarly, the country had taken up the challenge of increasing treatment success rate to $90 \%$ of all forms of non MDR -TB patients and to maintain at least $75 \%$ for MDR-TB cases by 2017. The NPTCCD is making relentless efforts in improving accessibility of TB treatment and care by engaging at least $50 \%$ of private healthcare providers by 2020 . Therefore, the engagement with civil society, involvement of TB survivors for mobilization, advocacy with media and field-based political \& faith leaders shall hold key to bringing about the desired evolution in the TB programme.

The country has also maintained a high treatment success rates since 2005 . The relentless efforts of the national TB programme, Ministry of Health also ensured appropriate response to TB-HIV co-infections and addressing multi drug resistant $\mathrm{TB}$, in a most comprehensive manner. Therefore, both these issues are by and large under control. Yet, TB continues to confront the nation as a major public health concern. Distribution of TB cases wide across various districts in the Island has a huge disparity, which is due to various socio-economic, cultural and environmental factors.

Varied scientific studies have demonstrated that the probability of contracting the disease is significantly and particularly higher among the economically vulnerable and the socially disadvantaged population groups due to increased exposure to active cases (Das \& Horton, 2010). The key strategies in interruption of transmission of TB include early identification and treatment of patients and tracing their respective contacts. Management of tuberculosis generally requires continuous treatment for a minimum of 6 months, which is usually escalated due to multi-drug resistant forms 


\section{Confronting Health Communication Challenges \\ Addressing Tuberculosis in Sri Lanka: Synopsis}

of the TB. Context-specific reasons to clustering of TB cases in urbanized communities need to be evaluated (WHO, 2010) and non-health intervention strategies such as social protection and urban planning ought to be the important elements of program planning (Hargreaves et al., 2011). Needless to emphasize, equally critical are the community empowering strategies of the ACSM, which are poised to engage with individuals, families and their communities through focused health communication on TB and the associated risk-factors. Like many other developing countries, Sri Lanka is relentlessly pursuing the TB Control goals and now gearing up with an equally significant emphasis on strategic health communication (ACSM for TB), including further strengthening prevention aspects of the disease, while relentlessly mitigating the associated stigma.

\section{GENDER DIMENSION}

Tuberculosis (TB) kills more women each year than any other infection. TB is the third cause of morbidity and mortality combined in women of reproductive age in developing countries and leads to more deaths in women than maternal mortality (Connolly \& Nunn, 1996). Prevalence of TB is similar in males and females until adolescence, when it increases in males (Hudelson, 1996). In high prevalence countries, however, women of reproductive age have higher rates of progression to disease than men in this age group.

In Sri Lanka in the current year, i.e. 2018, up to the $2^{\text {nd }}$ quarter, the reported TB cases in females were 1429 as compared to the male counterparts with 2627 reported cases. Hence, in the current year too, cases in females so far have been nearly half of the reported cases in the male counterparts (NPTCCD, Sri Lanka).

Gender differentials exist in reporting and diagnosing $\mathrm{TB}$, and passive case finding likely leads to under-diagnosis of TB in women. The socioeconomic consequences of TB in women are exacerbated by late presentation, which leads to a poor prognosis. The stigma associated with TB causes women to be divorced or to be unlikely to become married. A study in India found that male patients with TB expected their wives to care for them but infected wives rarely received care. Thus, married women may try to hide their symptoms instead of seeking help.

The national Strategic Plan for TB Control (2015-2020), Sri Lanka mentions that access to health is limited for women working in sectors like plantations and garment 
industry due to conditions prevailing in these occupations. Though HIV prevalence is not high when compared to other countries in the region, the increasing trend has been observed in the recent years. The majority affected are people in the reproductive age group. TB and HIV co-infection increases women's health risks: women living with HIV are highly susceptible to developing active TB during pregnancy or soon after delivery, thus making TB a leading cause of death during pregnancy and delivery, and thereafter too (NPTCCD, 2015).

The current efforts of the national TB programme are geared to lead to an increase in the number of people seeking health and practicing 'healthy behaviors' and thus, reaching out to health facilities, which is expected to promote better case-detection and perhaps on-start of timely treatments. Therefore, the focused health communication on TB in Sri Lanka is expected to serve as a strong link between the casedetection, TB treatment and the health-seeking behaviors of communities, including addressing associated stigma issues.

\section{TB COMMUNICATION: PROCESS AHEAD}

In the past four decades, health communication has evolved from Information, Education and Communication (IEC) to Behavior Change Communication (BCC) to Social and Behavior Change Communication (SBCC). IEC, as it was usually practiced, focused on delivering information to a target, with an inherent assumption that subsequent to delivering accurate information, people would reduce damaging or harmful behaviors and thus, adopt desired positive behaviors. BCC acknowledged that information is necessary but not sufficient in most cases. BCC uses contextspecific formative research to determine the motivators, barriers and facilitators to behavior change, and responds with a variety of techniques designed to incite the individuals to change their behavior.

All the successful behavior change interventions are built on an understanding of the complex social, cultural and economic factors that make up the multiple levels of determinants of health and health behavior. Two complementary (and sometimes overlapping) theories are used in designing behavior change interventions: explanatory or predictive theories, which examine why a particular behavior occurs; and change theories, which focus on how behaviors can be changed (Schmidt, 2014). Without a clear understanding of why people practice or don't practice a particular 


\section{Confronting Health Communication Challenges}

Addressing Tuberculosis in Sri Lanka: Synopsis

behavior, interventions are not likely to succeed. This also signifies the inherent need for integrating qualitative and formative research into any SBCC (social \& behavior change communication) design and interventions, which essentially bring forth the true human-faces behind the hidden statistical data.

In fostering sustained social and behavior change communication interventions in communities, within the gamut of development and health programmes, the proponents of various communication theories and frameworks have cited how social change takes place and how a positive and progressive change is communicated through select set of communication tools and channels over a period of time to individuals, communities and society.

It is assessed that the TB - ACSM is largely based on the socio-ecological model of strategic communication, wherein each of its pillars, i.e. (i) advocacy, (ii) communication \& (iii) social mobilization run vertical in the TB communication strategy, yet they are cohesively interlinked.

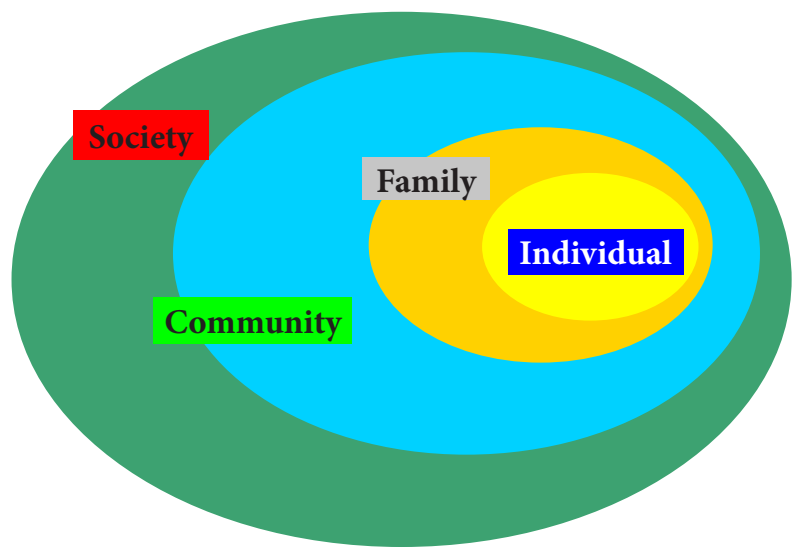

Figure 1. Theoretical \& Conceptual Frameworks | ACSM Sri Lanka

ACSM Sri Lanka (2018) utilizes the most appropriate set of health communication frameworks, wherein the Socio-Ecological Model is placed as a common denominator. The applied conceptual frameworks are: Health Belief Model - HBM (Hochbaum \& Rosenstock 1952); The Theory of Planned Behavior (Ajzen, 1991) and; The Stages of Change Model (Prochaska, DiClemente, \& Norcross, 1992).

The process of determining which conceptual-framework or communication approach to adopt in TB is considered to be a strategic and systematic endeavor. The 
designing of health communication programs, therefore, takes as its starting point, both the "felt needs" at the social system level, and the "action needs" as identified by development partners and key gate-keepers. And throughout this given process, are the people-centered participatory methods of engaging communities in defining behavior-change goals, designing field-based activities, identifying required material and key messages and in building bridges with the local influential communityleaders, which is pursued in designing Sri Lanka's ACSM strategic design (2018).

Translating and effectively converting technical-information and complex sociobehavioral messages into creative, appealing and acceptable approaches that trigger sustained dialogue among participants is often one of the most difficult and daunting tasks within the design and delivery of substantive and focused health communication (Gupta, 2014). Hence, communication takes as its starting point both the 'felt needs' at community or local level, and the 'action needs' as identified by stakeholders and gate-keepers.

The NPTCCD employed a scientific process of ACSM design (2018) that enabled reviewing of relevant literature on behavior change communications on $\mathrm{TB}$, in examining the research from the health and education sectors to identify effective behavior change strategies. Furthermore, the process of strategizing ACSM interventions imbibed the participatory methodology in engaging with TB Survivors, Patients, Health Providers, TB Specialists and District based Medical Officers. In addition, the risk-factor analysis was undertaken through qualitative formative assessment directly involving urban low-income population, factory workers, adolescent and youth groups and non-governmental organizations. Thus, the current process helped in ensuring that the ensuing ACSM interventions not only shall draw on the effective strategies and the primary conceptual frameworks for a focused TB health communication but are also people-centric, needs-based, results-driven and cost-effective.

NPTCCD's strategic vision for TB control in Sri Lanka is set to achieve universal access and treatment, i.e., all TB patients (or suspected TB positives) in the country should have access to early, good quality diagnosis and treatment services in a manner that is affordable and convenient to patients in time, place, and person. Inherent to this strategic vision is equity, social-inclusion and gender parity that also denotes, all the affected communities should have complete access to TB prevention, care, and treatment, including women and children, elderly, migrants, homeless, alcohol and other drug users, prison inmates, PLHIV, and those with other clinical risk factors. The program's ACSM strategy will truly complement every other program initiative 


\section{Confronting Health Communication Challenges \\ Addressing Tuberculosis in Sri Lanka: Synopsis}

for ensuring universal access, and be potentially used for better demand generation of early diagnosis and treatment, as well as sustained supply of quality care services. Therefore, the major components of ACSM 2018 strategy are:

- Advocacy for administrative and political \& faith leaders commitment and to keep TB control high on health and development agenda.

- Communication for demand generation (health-seeking behaviors) for case detection \& treatment and for mitigating stigma; audience segmentation, targeted behavior-change interventions, and community mobilization shall also reinforce increasing the demand for health services.

- Community ownership and mobilization for case finding and support to TB patients; on the supply side, multiple stakeholders, including various groups of health care providers, media, policy makers, NGOs, community-based organizations (CBOs), faith-based groups, other active community groups, local leaders (including gram-sevaks), etc., shall be targeted for improved provision of care.

One critical group for TB communication is the chest symptomatic patients or those with chronic cough to urge them on the need to go to DOTS clinic or a health facility for TB diagnosis. This would focus on the patients in the community but 'missing' from the health services or the TB program. For example, there are presently about 800,000 such cases in the community in India who are yet to be diagnosed or put on treatment. Without tracking them, there is certainly no way that TB can be eliminated.

\section{PREVENTION THROUGH HEALTH COMMUNICATION}

Approaches to the prevention and control of the HIV/AIDS epidemic across the globe, especially in Africa, have been largely based on previous experiences and examples from the industrialized countries, where it is documented that the disease affects some specific risk groups (De Cock, Mboru-Ngacha, \& Marum, 2002). Similarly, the TB infections that were earlier known as a "poor man's disease" are no more restricted to the shanty areas or to the people living below the poverty line. Varied individual behaviors, such as taking precautions while coughing or sneezing in public and starting the antibiotic TB treatment soonest are a common denominator to 
the TB Prevention. And such preventive behaviors in the communities, needless to emphasize, are fostered through well designed, researched and participatory Health Communication strategies. Such prevention efforts with the aid of strategic communication strategies are recommended internationally.

\section{SOCIAL INCLUSION \& 'INDIVIDUAL AT THE CENTER-STAGE' | ACSM}

The recently constituted TB ACSM strategic framework in Sri Lanka ought to keep the "individual" at the center-stage and bring family, community, and society under its purview to bring about desired changes in health (TB) perceptions and associated positive behaviors. Strategic inclusion of family, community and society facilitates and encourages behavioral changes. ACSM in the country proposed to use a mix of communication approaches, including large-scale mass media and local field-level communication interventions using mid-media and IPC, to their full potential.

Most social scientists and communication experts argue in support of the approach wherein the communities are stakeholders. As a 'bottom-up' design model for Health Communication planning, the current TB-ACSM approach is poised to inherently engage with the communities in designing, implementing and monitoring the TB health communication strategies and activities. A case in point is the recently initiated ACSM strategy process (2018), wherein the participatory methodology was employed for bottoms-up design of interventions. Therefore, the true human-centered development (and health) has to be achieved from grassroots to up as 'patting the lost first' is needed in community development (Handaragama \& Rasnayake, 2011). The ensuing ACSM activities shall ensure active participation of the target-audiences/beneficiaries contributing to the quality and sustainability of the TB prevention \& care interventions.

\section{REVIEWING LIMITATIONS | ACSM (NATIONAL STRATEGIC PLAN FOR TB CONTROL: 2015-2020)}

Section 5.13 of the National Strategic Plan For Tuberculosis Control (2015-2020), NPTCCD illustrates some critical gaps in the on-going ACSM efforts under the TB Control programme. The current ACSM mission (NPTCCD/2018) has reviewed 


\section{Confronting Health Communication Challenges \\ Addressing Tuberculosis in Sri Lanka: Synopsis}

the flagged gaps and recognizes the strategic need to address these through focused ACSM interventions, both at the field level and at the national level with the overarching Campaign interventions.

Community and civil society engagement through advocacy, communication and social mobilization is part of the National TB control activities and District TB Control Officers are responsible for activities for awareness among the general public. The TB guidelines advise the DTCO to engage with NGOs, private practitioners and private hospitals and plan for their involvement in TB care services. Involving community volunteers, community leaders and civil society is part of role of the DTCO for providing patient support services. Some specific gaps related to advocacy, communication and social mobilization have been identified by the National Strategic Plan for TB Control:

$>$ Only limited activities are planned at district level for awareness generation and sensitization on a regular basis.

$>$ TB posters are not displayed at appropriate places in health institutions.

$>$ Mass awareness programs and local awareness meetings with community are not being organized by the DTCOs.

$>$ There is limited participation and involvement of general practitioners, pediatricians, local clinical societies/medical associations, medical colleges/faculties and army/police on TB awareness and advocacy.

$>$ There is limited advocacy and engagement with relevant social departments for TB patients to avail social support benefits and facilities (NPTCCD, 2015).

Like many developing countries, Tuberculosis continues to pose a significant challenge to health planners in Sri Lanka. Relatively weak link with health communication, including a lesser degree of public engagement, is largely accorded as one of the major factors impeding the otherwise relentless efforts being made in the TB control. Therefore, the ACSM strategy framework in Sri Lanka addresses four key challenges and thus fosters: (i) improving case detection and treatment adherence; (ii) reducing stigma \& discrimination; (iii) empowering TB patients; and (iv) mobilizing the required resources and political commitment needed to combat $\mathrm{TB}$. It is noteworthy that the ACSM activities are an important and inherent element to achieving universal access to high quality care for those suffering with TB. 


\section{PARTICIPATORY MODEL | ACSM DESIGN}

Comprehensive desk analysis - as a part of skills-building training in ACSM design \& implementation - led to engagement with the DDTCOs, MOs \& NGOs. And like true soldiers of TB advocacy, these participants relentlessly pursued the pre-selected key groups to review risk-factors, identify their most accessible communication channels/tools, spot priority messages, assess their life-styles and which "benefit-messages" are these select groups best connected to. The key observations made during the ACSM field-work subsequently emanated with an ACSM ResultsChain/Log Frame (2018) for Sri Lanka.

In addition to the mass audiences (General Populations), the priority key intended clients (audiences) of the ACSM were flagged as:

(a) General Populations, with a strategic focus on Rehab clusters and urban lowincome group settlements

(b) Adolescents \& Youth groups

(c) Entire chain of Health Providers

(d) TB Survivors \& Patients

(e) Workers and Labor Force in Industries/Factories/SEZ areas etc.

In Sri Lanka, the ACSM conceptual framework (2018) is based on the strategic communication approach, addressing core needs of advocacy, behavior development/change and community mobilization, thus fostering TB prevention, treatment \& care strategies and stigma mitigation. Such an approach is based on a premise that individual-level behavior change does not occur in an isolation; rather individuals are influenced by family members, peers, community, and prevailing social and cultural practices/mindsets. With such an emerging approach, it is of paramount importance that Advocacy, Communication and Social Mobilization initiatives are well stratified, both horizontally and vertically. In other words, initiatives would occur at national, provincial/district and local levels, while building multiple partnerships. And generating resources is critical to a sustained management of the TB-ACSM in the country.

The field-work and skills-building exercise earmarked and committed to an acclaimed and promised TB elimination target of 2025 in Sri Lanka, while the process defined the purpose as, 'Fostering socially-inclusive, equity based and people centric TB communication programmes in addressing enhanced case-detection, sustained treat- 
ment adherence, comprehensive prevention practices and reduced stigma'. To attain the defined purpose of the TB-ACSM in Sri Lanka, the select technical group earmarked the four expected outcomes, i.e. (i) Through high-level political \& faith-based support and adequate resources, people possess complete and correct knowledge on TB prevention \& treatment, ensuring practicing safer \& preventive health behaviors and mitigating (remove) associated stigma in the communities; (ii) High-risk populations are empowered with positive health messages leading them to access nearest health facilities for testing and adhering to the required treatment; (iii) Highly pro-active and engaged TB survivors and the current patients serve 'Positive Deviants' as strong advocates of the TB Programme for early and timely detection, ease of adherence to complete treatment and mitigating any associated stigma; (iv) Health providers fully empowered with prevention practices at-work and foster stigma-free TB treatment \& cure as change-agents in communities.

The ACSM (2018) in Sri Lanka, based on field assessment, desk-based analysis, critical observations and, formative research with the intended audiences - as relentlessly conducted by the trained District TB officers, MOs and NGOs representatives - emerged with a few technical recommendations, which are synoptically presented in this paper:

\begin{tabular}{|l|l|}
\hline Observation \& Recommendation & \multicolumn{1}{c|}{$\begin{array}{c}\text { Actionable Strategies } \\
\text { (National level) }\end{array}$} \\
\hline $\begin{array}{l}\text { Enter-Educate approach - design } \\
\text { a national campaign intervention }\end{array}$ & $\begin{array}{l}\text { A nation-wide, entertainment based, multi-structured and with multiple me- } \\
\text { dia tools national campaign, which shall include selected primary messages } \\
\text { on TB. This innovative campaign shall serve as an overarching umbrella to all } \\
\text { the other field-based ACSM interventions. }\end{array}$ \\
\hline $\begin{array}{l}\text { A Common 'Branding' Tagline for } \\
\text { all the TB ACSM Materials }\end{array}$ & $\begin{array}{l}\text { An all encompassing 'benefit message' as a common campaign tagline, i.e. } \\
\text { "if timely acted upon, TB is completely curable with a simple and regular } \\
\text { medication taken for a prescribed period that is available at the nearest health } \\
\text { facility" suggested for use in every TB-ACSM material, stationary and health } \\
\text { promotion products. Such a repeated reassuring message shall go a long way } \\
\text { in addressing prevailing stigma issues as well. }\end{array}$ \\
\hline Political Collective - TB Coalition & $\begin{array}{l}\text { Formation of a political collective, especially constituting Medical Parliamen- } \\
\text { tarians; Convening a quarterly meeting with elected leaders shall position TB } \\
\text { issues high on national agenda. }\end{array}$ \\
\hline
\end{tabular}

1 Select observations and recommendations are drawn from the field work and formative research done by the TB specialists, NGOs and others during the ACSM mission-2018. 


\section{Deepak Gupta, Kanthi Ariyarathne, Abdul Cader Refai, Shyamali Rathnayake}

\begin{tabular}{|c|c|}
\hline Enhanced Media Engagement & $\begin{array}{l}\text { Media is located at the interface between public and policy agendas thus, } \\
\text { plays a major role in setting policy agendas. It also provides a window into is- } \\
\text { sues concerning the general population and helping influence policy agendas } \\
\text { by focusing public attention on particular issues, such as TB. Therefore, the } \\
\text { media could play a role in framing policy debates about major health reform } \\
\text { issues, especially in maintaining momentum for disease control. }\end{array}$ \\
\hline $\begin{array}{l}\text { 'Positive Deviants'(TB Survivors) } \\
\text { in TB Programme }\end{array}$ & $\begin{array}{l}\text { The TB Survivors who have successfully completed the treatment and those } \\
\text { who represent the same community where the other "laggards" or people } \\
\text { with misconceptions and lack of information are situated, are positioned } \\
\text { strategically in playing the much desired catalytic role in the TB ASCM } \\
\text { programme. }\end{array}$ \\
\hline $\begin{array}{l}\text { Goodwill Advocates - Enhanced } \\
\text { Outreach | Connecting 'Voices' of } \\
\text { People }\end{array}$ & $\begin{array}{l}\text { Well-known figures help the issue in amplifying the message, generating } \\
\text { more funds, expanding partnerships and, most significantly so, catching } \\
\text { eye-balls to the cause. Hence, for enhancing people's engagement with the } \\
\text { TB prevention and timely treatment and also the associated stigma concerns } \\
\text { in Sri Lanka, the ACSM mission recommends NPTCCD/MoH to explore } \\
\text { possibilities of bringing a Cricketer and a Movie/TV star on board with the } \\
\text { TB Control programme }\end{array}$ \\
\hline $\begin{array}{l}\text { Formation of Technical Support } \\
\text { Unit (TSU) Steering ACSM | } \\
\text { NPTCCD }\end{array}$ & $\begin{array}{l}\text { In addressing the critical needs of behavior-marketing, demand-generation } \\
\text { of TB care \& treatment and in mitigating stigma issues, a full-fledged } \\
\text { dedicated TSU located within the NPTCCD is recommended. Such a highly } \\
\text { specialized unit shall comprise of 'creative professionals' such as health } \\
\text { communication \& marketing specialists, social scientists, experienced } \\
\text { campaigners and TB advocates. The unit shall have a clearly etched road-map } \\
\text { of researching, designing, planning, executing, coordinating and monitoring } \\
\text { of focused ACSM interventions and the ensuing national campaign - as a } \\
\text { 'Campaign Secretariat ("war room"). }\end{array}$ \\
\hline $\begin{array}{l}\text { Quarterly Monitoring | Streamlin- } \\
\text { ing ACSM }\end{array}$ & $\begin{array}{l}\text { The central ACSM coordination group shall earmark specific achievable } \\
\text { benchmarks which could be reviewed through a quarterly mechanism. Such } \\
\text { a quarterly review may like to involve multiple partners in the review exercise } \\
\text { and seek solutions wherever the impediments are spotted, if any }\end{array}$ \\
\hline $\begin{array}{l}\text { Capacity Development - devising } \\
\text { local indicators and designing } \\
\text { communication }\end{array}$ & $\begin{array}{l}\text { The gatekeepers of the TB communication interventions and the civil society } \\
\text { partners - situated at the field-level - be thoroughly trained in and engaged } \\
\text { with hands-on skills building in shaping up M\&E indicators and imple- } \\
\text { mentation processes. This is more so as the TB Communication indicators } \\
\text { and various new-age and simple-to-follow methodologies need to be locally } \\
\text { developed and be contextualized to the local realities }\end{array}$ \\
\hline $\begin{array}{l}\text { TB Communication 'Audit' - Bi- } \\
\text { Yearly or Annually }\end{array}$ & $\begin{array}{l}\text { Are we reaching the right audiences and with the right messages in TB Com- } \\
\text { munication? Is our message consistent and leading to affirmative action? Is } \\
\text { our ACSM actually addressing the inherent concerns \& risks of the 'Clients', } \\
\text { 'Gatekeepers' and 'Stakeholders' under the TB Control programme? To deter- } \\
\text { mine whether we are on the right path as was envisaged and whether the sub- } \\
\text { scribed communications tools are working well, we need a yearly Communi- } \\
\text { cations Audit: a snapshot of TB's Outreach \& Communications interventions, } \\
\text { strategies, activities and programs. }\end{array}$ \\
\hline
\end{tabular}




\section{REFERENCES}

Connolly, M., \& Nunn, P. (1996). Women and tuberculosis. World Health Stat Q, 49(2):115-9. Review. PubMed PMID: 9050189.

Das, P., \& Horton, R. (2010). Tuberculosis - time to accelerate progress. Lancet. 375(9728),1755-1757. doi:10.1016/S0140-6736(10)60600-9

De Cock, K. M., Mbori-Ngacha, D., \& Marum, E. (2002). Shadow on the continent: public health and HIV/AIDS in Africa in the 21st century. Lancet, 360(9326), 67-72.

Gupta, D. (2014). Polio Eradication Campaign in the NCR of Delhi. Research \& Doctoral Unit (pp. 92-97). SOJNMS.

Handaragama, S., \& Rasnayake, S. (2011). Development Sociology. Baththaramulla: Sameera Publications.

Hargreaves, J. R., Boccia, D., Evans, C. A., Adato, M., Petticrew, M., \& Porter, J. D. (2011). The social determinants of tuberculosis: from evidence to action. American Journal of Public Health, 101(4), 654-62. doi:10.2105/AJPH.2010.199505

Hudelson, P. (1996). Gender differentials in tuberculosis: the role of socio-economic and cultural factors. Tuber Lung Dis, 77(5), 391-400. Review. PubMed PMID: 8959141.

NPTCCD (2015). National Strategic Plan for TB Control 2015-2020. Sri Lanka: Ministry of Health.

Shmidt, K. (2014). Applying Lessons from Behavior Change Communications to the Design of an Intervention Promoting Family and Community Support for Learning to Read. Education Data for Decision Making (EdData II), Task Order 20. Report. RTI International. Retrieved from https://www.globalreadingnetwork. net/publications-and-research/task-order-20-measurement-and-research-support-education-strategy-goal-1

WHO (2010). Equity, social determinants and public health Programmes (pp. 220-37). Geneva: World Health Organization. 
Deepak Gupta, Kanthi Ariyarathne, Abdul Cader Refai, Shyamali Rathnayake

WHO (2016). Global Tuberculosis Report 2016. Switzerland: World Health Organization.

WHO (2017). Bending the Curve, Ending TB: Anual Report 2017. India: Regional Office for South - East Asia, World Health Organization 